\author{
ARTIGO \\ dO $\underline{\text { https://doi.org/10.22481/praxisedu.v16i41.6253 }}$
}

\title{
ESPAÇO E LETRAMENTO NOS TRÊS PRIMEIROS ANOS DO ENSINO FUNDAMENTAL: A REALIDADE OBSERVADA
}

\author{
SPACE AND LITERACY IN THE FIRST FIRST YEARS OF KEY EDUCATION: THE \\ OBSERVED REALITY
}

\section{ESPACIO Y LETRAMIENTO EN LOS PRIMEROS PRIMEROS AÑOS DE EDUCACIÓN: LA REALIDAD OBSERVADA}

\author{
Lucia Hugo Uczak \\ Universidade Feevale - Brasil \\ Karine Oliveira Faller \\ Universidade Feevale - Brasil
}

\begin{abstract}
Resumo: Este artigo é parte de uma pesquisa maior, de abordagem qualitativa, que abrange estudos sobre alfabetização e letramento. O objetivo deste texto é apresentar algumas considerações sobre a forma como os professores do bloco pedagógico, que compreende os três primeiros anos do Ensino Fundamental, vem utilizando o espaço de sala de aula como estratégia para o letramento. O campo empírico do estudo é uma escola pública municipal. Buscamos o embasamento legal para explicar a organização e o objetivo do bloco de alfabetização e abordamos o letramento como processo em constante desenvolvimento na aprendizagem escolar, de modo especial, nas atividades lúdicas. Ao relacionar as Diretrizes Curriculares Nacionais para o Ensino Fundamental de Nove Anos com as evidências levantadas a partir da coleta de dados, foi possível perceber divergências entre o que a legislação determina para esta etapa e o que está acontecendo na prática, na escola observada. $\mathrm{O}$ trabalho com o letramento realizado em um ambiente propício às interações, dando continuidade à Educação Infantil, marcada pelos processos de aprendizagem a partir das vivências, fica registrado apenas no Projeto Político Pedagógico, mas é pouco observado nas práticas pedagógicas. A repetição toma o lugar das brincadeiras, a diversidade de textos perde espaço para fragmentação de palavras e assim, isso acaba refletindo na pouca exploração do espaço de sala de aula, já que as intervenções pouco promovem momentos lúdicos e de interação. Utilizamos como aporte teórico os estudos de Soares $(2014 ;$ 2017), Becker (1993; 2001), Ferreiro (1991), entre outros.
\end{abstract}

Palavras-chave: Alfabetização; Letramento; Espaço; Ludicidade.

Abstract: This article is part of a larger research, of qualitative approach, covering studies on acquisition of reading and writing and literacy. The purpose of this paper is to present some considerations on how the teachers of the pedagogical block, which comprehends the first three years of Elementary School, have been using the classroom space as a strategy for literacy. The empirical field of this study is a municipal public school. We sought the legal basis to explain the organization and purpose of the literacy block and approached the literacy as a process in constant development in 
school learning, in a especial way, in recreational activities. By relating the National Curriculum Guidelines for the Elementary School of Nine Years with the evidence gathered from the data collection, it was possible to notice divergences between what the legislation determines for this stage and what is happening in practice in the observed school. The work with literacy carried out in an ideal environment to interactions, continuing the early Childhood Education, marked by learning processes from experiences, is recorded only in the Pedagogical Political Project, but is little observed in pedagogical practices. Repetition takes the place the plays, text diversity loses space for word fragmentation and thus, this ends up reflecting on the little exploration of the classroom space, since the interventions promote little playful moments and interaction. We used the theoretical studies of Soares (2014; 2017), Becker (1993; 2001), Ferreiro (1991), among others.

Keywords: Reading and writing acquisition; Literacy; Space; Playfulness.

Resumen: Este artículo es parte de un enfoque de investigación cualitativa más amplio que cubre la alfabetización y los estudios de alfabetización. El propósito de este texto es presentar algunas consideraciones sobre cómo los profesores del bloque pedagógico, que comprende los tres primeros años de educación primaria, han estado utilizando el espacio del aula como estrategia para la alfabetización. El campo empírico es una escuela pública municipal. Buscamos la base legal para explicar la organización y el objetivo del bloque de alfabetización y abordar la alfabetización como un proceso en constante desarrollo en el aprendizaje escolar, especialmente en las actividades recreativas. Al relacionar las Pautas Curriculares Nacionales para los Nueve Años de Educación Primaria con la evidencia obtenida de la recolección de datos, fue posible notar divergencias entre lo que la legislación determina para esta etapa y lo que está sucediendo en la práctica. El trabajo con la alfabetización realizado en un ambiente propicio para las interacciones, dando continuidad a la Educación Infantil Temprana, marcada por procesos de aprendizaje a partir de experiencias, se registra sólo en los Proyectos Políticos Pedagógicos, pero es poco observado en las prácticas pedagógicas. La repetición sustituye al chiste, la diversidad de los textos pierde espacio para la fragmentación de las palabras y, por lo tanto, termina por reflexionar sobre la escasa exploración del espacio del aula, ya que las intervenciones no promueven momentos de juego e interacción. Utilizamos los estudios teóricos de Soares $(2014 ;$ 2017), Becker (1993; 2001), Ferreiro (1991), entre otros.

Palabras clave: Alfabetización; Letramiento; Espacio; Ludicidad.

\section{Introdução}

Neste artigo apresentamos e discutimos a forma como os professores dos três primeiros anos do Ensino Fundamental têm utilizado o espaço de sala de aula como um recurso para oportunizar propostas de trabalho com o letramento.

Iniciamos o texto buscando uma breve contextualização quanto aos documentos legais que estabelecem as Diretrizes Curriculares Nacionais para o Ensino Fundamental de Nove Anos destacando as orientações emanadas pelo Conselho Nacional de Educação para a organização do ciclo de alfabetização ou, também referido, bloco pedagógico. Evidenciamos a importância da organização do espaço da sala de aula de modo a colocar as crianças em contato com um ambiente lúdico e convidativo para o desenvolvimento de práticas relacionadas à leitura, escrita e utilização desses códigos em seu cotidiano. Discutimos o letramento, em especial, a partir dos estudos de Magda Soares, uma das mais importantes 
especialistas da área em nosso país. Com base em seus estudos entendemos o letramento como "um estado, uma condição: o estado ou condição de quem interage com diferentes portadores de leitura e escrita, com diferentes gêneros de leitura e de escrita, com as diferentes funções que a leitura e a escrita desempenham em nossa vida” (SOARES, 2014, p. 44). Já alfabetização é explicada pela mesma autora como o processo de apropriação da tecnologia da leitura e da escrita, ou seja, o domínio do código pelo sujeito. A compreensão dos conceitos 'alfabetização e letramento' por parte dos docentes é fundamental para elaboração de um planejamento adequado visando a aprendizagem plena e sucesso das crianças nesta etapa da escolarização.

No recorte abordado neste artigo, que integra uma pesquisa qualitativa, a coleta de dados se deu através de análise documental - Projeto Político Pedagógico (PPP) da escola participante, observações dos espaços de sala de aula dos três anos do ciclo, e da prática docente. Estes dados foram coletados em uma escola pública, integrante da rede municipal de um município do Vale do Rio dos Sinos, no estado do Rio Grande do Sul. A participação da escola foi voluntária. Foram realizadas duas observações com a duração de um turno de aula, em cada uma das turmas, totalizando seis observações, registradas em um diário de campo (DC) da pesquisa. Já com as três professoras foram realizadas entrevistas semiestruturadas, individuais, em espaço previamente organizado para isso. A participação das professoras foi voluntária, após uma das pesquisadoras explicar a proposta do estudo, em reunião com a coordenação pedagógica e as docentes do ciclo de alfabetização. Para conhecer a opinião das crianças envolvidas no ciclo de alfabetização optou-se pela realização de uma proposta lúdica, desenvolvida em três encontros, com um grupo focal de cada ano do ciclo: na turma de primeiro ano, o grupo continha seis crianças, na de segundo ano sete crianças e na de terceiro ano, oito crianças. A indicação das crianças foi feita pelas professoras de cada turma. No total, foram realizados nove encontros, com vinte e uma crianças do ciclo.

A fim de preservar a identidade dos participantes da pesquisa, conforme assegurado no Termo de Consentimento Livre e Esclarecido (TCLE), foi utilizada uma legenda para identificação das falas, apresentada no quadro abaixo:

Quadro 1 - Participantes da pesquisa

\begin{tabular}{|l|c|}
\hline Participante & Legenda \\
\hline Pesquisadora & $\mathrm{P}$ \\
\hline $\begin{array}{l}\text { Professora do Primeiro Ano (formação em Magistério, 2 anos de atuação no } \\
\text { bloco pedagógico) }\end{array}$ & $\mathrm{P} 1$ \\
\hline $\begin{array}{l}\text { Professora do Segundo Ano (formação em Letras, 12 anos de atuação no bloco } \\
\text { pedagógico) }\end{array}$ & $\mathrm{P} 2$ \\
\hline
\end{tabular}




\begin{tabular}{|l|c|}
\hline $\begin{array}{l}\text { Professora do Terceiro Ano (formação em Magistério, Pedagogia e pós- } \\
\text { graduação em Psicopedagogia, } 19 \text { anos de atuação no bloco pedagógico) }\end{array}$ & P3 \\
\hline Criança do Primeiro Ano & C1 \\
\hline Criança do Segundo Ano & C2 \\
\hline Criança do Terceiro Ano & C3 \\
\hline
\end{tabular}

Fonte: Elaborado pelas pesquisadoras (2019)

Após a coleta dos dados, foi possível fazer relação entre as práticas pedagógicas das professoras e a organização do espaço de sala de aula que utilizavam, já que o ambiente reflete seus métodos e concepções epistemológicas (BECKER, 1993).

\section{O espaço dado ao letramento nas práticas docentes do bloco pedagógico}

De acordo com as Diretrizes Curriculares Nacionais para o Ensino Fundamental de Nove Anos, apresentadas pelo Parecer 11/2010 do Conselho Nacional de Educação, esta etapa de ensino tem sido foco central de políticas para garantia do direito à educação, assim como para melhoria de sua qualidade acompanhada da ampliação dessa oferta. Uma das medidas mais significativas nesse sentido foi a obrigatoriedade da matrícula de crianças com 6 (seis) anos de idade no Ensino Fundamental, o que gerou para as escolas brasileiras a necessidade de elaboração de um novo currículo e um novo projeto político pedagógico, pois:

A entrada de crianças de 6 (seis) anos no Ensino Fundamental implica assegurar-lhe garantia de aprendizagem e desenvolvimento pleno, atentando para a grande diversidade social, cultural e individual dos alunos, o que demanda espaços e tempos diversos de aprendizagem. Na perspectiva da continuidade do processo educativo proporcionada pelo alargamento da Educação Básica, o Ensino Fundamental terá muito a ganhar se absorver da Educação Infantil a necessidade de recuperar o caráter lúdico da aprendizagem, particularmente entre as crianças de 6 (seis) a 10 (dez) anos que frequentam as suas classes, tornando as aulas menos repetitivas, mais prazerosas e desafiadoras e levando à participação ativa dos alunos [...] (BRASIL, 2010, p.21).

Além da ludicidade e dinâmica das aulas, as referidas Diretrizes também asseguram que os três primeiros anos do Ensino Fundamental devem ser organizados em forma de ciclo ou de um bloco pedagógico, e que seja ininterrupto, pois esta etapa é destinada aos processos que envolvem a aquisição da linguagem escrita. Ou seja, o foco deste ciclo são os processos de alfabetização e letramento, que embora sejam processos distintos devem se dar em concomitância. Mas, afinal, em que consistem esses processos? 
Soares (2014) explica que a diferença entre eles é pontual: alfabetização compreende a capacidade do sujeito em codificar e decodificar o código escrito, ou seja, ler e escrever. Porém, o letramento faz com que este sujeito compreenda a função da escrita e dela faça uso em suas ações em meio à sociedade. A autora escreve que:

[...] um indivíduo alfabetizado não é necessariamente um indivíduo letrado; alfabetizado é aquele indivíduo que sabe ler e escrever; já o indivíduo letrado, o indivíduo que vive em estado de letramento, é não só aquele que sabe ler e escrever, mas aquele que usa socialmente a leitura e a escrita, pratica a leitura e a escrita, responde adequadamente às demandas sociais de leitura e de escrita. (SOARES, 2014, p. 39-40).

A partir do exposto podemos entender que existem diferenças relevantes entre esses processos e que, no avanço dos estudos sobre alfabetização foi-se constatando que esse termo passou a ser insuficiente para compreender as diferentes facetas nele envolvida, como explica Mortatti (2007, p.160),

[...] o esgotamento das possibilidades de o termo "alfabetização" designar algo mais do que a mera aquisição inicial da técnica ou habilidade de leitura e escrita, ou seja, para designar a condição de pessoas ou grupos que não apenas sabem ler e escrever, mas também utilizam a leitura e escrita e seus usos e funções sociais [...]

Compreendendo as diferenças entre processos podemos afirmar, assim como Soares (2014), que é possível ampliar o processo de letramento, mesmo ainda não tendo concluído o processo de alfabetização, pois é possível que uma criança compreenda as funções da escrita antes mesmo de estar alfabetizada. A autora exemplifica:

[...] a criança ainda não se alfabetizou, mas já folheia livros, finge lê-los, brinca de escrever, ouve histórias que lhe são lidas, está rodeada de material escrito e percebe seu uso e função, essa criança é ainda "analfabeta", porque não aprendeu a ler e a escrever, mas já penetrou no mundo do letramento, já é, de certa forma, letrada. [...] (SOARES, 2014, p.24)

Com base no exposto, ressaltamos a necessidade de uma prática pedagógica que tenha entre seus objetivos não apenas a codificação e decodificação, a compreensão de letras e seus respectivos fonemas. Assim como também, não basta a exposição de diferentes textos, mas que o sujeito aprendente possa interiorizar que há diversos gêneros textuais com diferentes funções, e que este consiga diferenciá-los e utilizá-los para além do ambiente escolar.

Assim o professor demonstra completa compreensão sobre sua função de educador do bloco pedagógico, conseguindo abranger ambos os processos, definidos por Carvalho (2005, p. 65) como: "Alfabetizar é ensinar o código alfabético, letrar é familiarizar o aprendiz com os 
diversos usos sociais da leitura escrita." Esta definição da autora salienta o papel do professor como mediador neste processo de aprendizagem, fazendo com que, ao longo do ciclo de alfabetização seja possível a consolidação da alfabetização e a ampliação do letramento.

Assim, entendemos que o processo de alfabetização se consolida até o terceiro ano do Ensino Fundamental, porém, o processo de letramento está em constante ampliação, à medida que o sujeito conhece novos gêneros textuais e os utiliza comunicando-se por meio da escrita. Para isso, faz-se necessário que o educador disponibilize em suas práticas pedagógicas a oportunidade de seus alunos terem acesso a diferentes formas de linguagem escrita e se responsabilize por promover momentos de leitura e escrita autoral, de forma prazerosa:

Trata-se, portanto, de uma perspectiva de trabalho que insira as crianças desde muito cedo, na cultura escrita, no mundo letrado. É preciso trabalhar, na escola, a natureza, os sentidos, as funções, os usos sociais da língua escrita na sociedade; desenvolver o amor pela leitura e pelos livros; trabalhar no sentido de mostrar que a leitura é informação, é conhecimento, emoção, diversão, entretenimento, imaginação, etc., e que escrita é registro, memória, comunicação, história, etc. É preciso apresentar a escrita não como um ato motor, mas como uma atividade cultural complexa. Mostrar que a escrita é um sistema de representação complexo da linguagem, um sistema simbólico, uma forma de expressão, um objeto cultural. (PERES, 2012, p.64)

Nesse sentido, cabe ao profissional docente proporcionar, no contexto educativo, elementos que possam enriquecer de significados a vida dos educandos, de forma que sejam capazes de ler, compreender e interpretar as mais diferentes formas de linguagem e comunicação, isto é, que sejam letrados, que possam utilizar dessas habilidades dentro do seu contexto social. Este enfoque é relativamente recente na educação brasileira, como afirma Soares (2014, p. 20):

[...] só recentemente passamos a enfrentar essa nova realidade social em que não basta apenas saber ler e escrever, é preciso também saber fazer uso do ler e do escrever, saber responder às exigências de leitura e de escrita que a sociedade faz continuamente - daí o surgimento do termo letramento.

Diante do exposto, cabe também destacar a necessidade de um cuidado do professor em suas práticas pedagógicas no ciclo, pois, muito mais do que propiciar momentos de contato com diversas formas de linguagem escrita, é indispensável que seja estimulada nos educandos a confiança na escrita autoral, na expressão por meio desta perante a sociedade.

Para que isso ocorra, é necessário que a utilização da escrita como meio de comunicação se torne algo rotineiro e natural, para que possa se tornar parte da vida fora da escola também. Rangel (2012, p.123) salienta que "[...] uma das tarefas da escola é ampliar o 
contato da criança com a cultura escrita, é fundamental que proporcione uma diversidade de situações e uma variedade textual [...]."

Ao encontro dessa ideia, Cardoso (2007) se atenta a enfatizar o quão necessário é que se crie canais de comunicação para além de aluno e professor, para que seja possível uma melhor compreensão acerca da função da escrita. Para isso, é importante que as práticas de escrita e leitura não se resumam apenas a redações, ou outros textos escritos em que apenas o professor possa ler e então corrigir, mas sim, a textos que possuam destinatários e possíveis respostas. De acordo com essa afirmativa:

A vivência nas práticas de leitura e produção textual reafirma, constantemente, um destinatário quase exclusivo para os textos das crianças. Ao longo de sua escolarização, elas vão constituindo uma concepção de interlocutor - o professor/leitor - que tem expectativas bem definidas em relação à sua produção escrita: ensinar, corrigir, avaliar. [...] (CARDOSO, 2007, p.43)

Dentre os documentos que norteiam a organização do planejamento bloco pedagógico está a Base Nacional Comum Curricular (BNCC) que estabelece como objetivos do processo de aprendizagem dos dois primeiros anos do Ensino Fundamental: "Identificar a função social de textos que circulam em campos da vida social dos quais participa cotidianamente [...] Localizar informações explícitas em textos [...] Editar a versão final do texto, em colaboração com os colegas e com a ajuda do professor, ilustrando, quando for necessário [...]" (BRASL, 2017, p.93). Assim, pode-se identificar diversas habilidades que os processos de alfabetização e letramento podem desenvolver no educando nesta fase. Também são objetivos relacionados à prática letrada:

[...] Ler e compreender, em colaboração com os colegas e com a ajuda do professor e, mais tarde, de maneira autônoma, textos narrativos de maior porte como contos (populares, de fadas, acumulativos, de assombração etc) e crônicas. [...] Apreciar poemas visuais e concretos, observando efeitos de sentido criados pelo formato do texto na página [...]. (BRASIL, 2017, p.95)

Estes objetivos aqui citados, e outros encontrados na Base Nacional Comum Curricular, vão ao encontro do mundo letrado, que exige do professor possibilitar que os alunos possam conhecer e explorar os mais diversos tipos de textos, identificando suas semelhanças e diferenças, mas acima de tudo, compreendendo e sabendo interpretar o que cada texto está trazendo. Cabe ainda destacar algumas habilidades que a Base Nacional Comum Curricular objetiva desenvolver: 
[...] Ler e compreender, em colaboração com os colegas e com a ajuda do professor ou com certa autonomia, listas, agendas, calendários, avisos, convites, receitas, instruções de montagem (digitais ou impressos), dentre outros gêneros do campo da vida cotidiana [...] Ler e compreender em colaboração com os colegas e com a ajuda do professor, quadras, quadrinhas, parlendas, trava-línguas, dentre outros gêneros da vida cotidiana [...] Ler e compreender com certa autonomia cantigas, letras de canção, dentre outros gêneros do campo da vida cotidiana, considerando a situação comunicativa e o tema/assunto do texto e relacionando sua forma de organização à sua finalidade. (BRASIL, 2017, p.101)

Além de conhecer os mais diversos tipos de gêneros textuais, o processo de letramento possibilita que os sujeitos também possam desenvolver a capacidade de produzir textos de diferentes gêneros podendo então, expressar-se através da língua escrita. Diante do exposto, a Base Nacional Comum Curricular traz em seus objetivos:

[...] Planejar e produzir bilhetes e cartas, em meio impresso e/ou digital, dentre outros gêneros da vida cotidiana [...] Planejar e produzir pequenos relatos de observação de processos, de fatos, de experiências pessoais [...] Planejar e produzir, em colaboração com colegas e com a ajuda do professor, (re)contagens de histórias, poemas e outros textos versificados (letras de canção, quadrinhas, cordel) poemas visuais, tiras e histórias em quadrinhos [...] Planejar e produzir, em colaboração com os colegas e com a ajuda do professor, recados, avisos, convites, receitas, instruções de montagem [...] (BRASIL, 2017, p.101).

É de suma importância também que os alunos conheçam e explorem textos informativos e que consigam desenvolver ainda a habilidade de discorrer sobre esse tipo de texto. $\mathrm{O}$ processo de letramento concomitante ao processo de alfabetização determina o conhecimento dos gêneros textuais e suas funções. Conforme a BNCC:

[...] Reconhecer a função de textos utilizados para informações coletados para apresentar informações coletadas em atividades de pesquisa (enquetes, pequenas entrevistas, registros de experimentações). [...] Explorar, com a mediação do professor, textos informativos de diferentes ambientes digitais de pesquisa, conhecendo suas possibilidades. (BRASIL, 2017, p.107)

Para a criação desse contexto educativo é necessário pensar na elaboração do ambiente assim como na construção do espaço em que acontece esse processo, espaço esse que deve favorecer o aprendizado em conjunto. Pensa-se muito na estruturação do ambiente para a Educação Infantil, e o mesmo não acontece com os anos iniciais do Ensino Fundamental, sendo que estes, da mesma forma, necessitam de uma didática voltada para o lúdico, já que também atendem sujeitos na fase da infância e esses devem sentir-se parte do processo de ensino e aprendizagem. Nesta perspectiva: 
[...] não basta a criança estar em um espaço organizado de modo a desafiar suas competências; é preciso que ela interaja com esse espaço para vivê-lo intencionalmente. Isso quer dizer que essas vivências, na realidade, estruturam-se em uma rede de relações e expressam-se em papéis que as crianças desempenham em um contexto no qual os móveis, os materiais, os rituais de rotina, a professora e a vida das crianças fora da escola interferem nessas vivências (ROSSETTI-FERREIRA, 1999 apud HORN, 2004, p.15).

Sendo assim, torna-se extremamente relevante que as práticas pedagógicas busquem as possibilidades de explorar o ambiente de uma forma didática nesse etapa da vida escolar em que o sujeito se alfabetiza; afinal, esta preparação do espaço, tão discutida na Educação Infantil, também deve ser alvo de preocupação nos primeiros anos do Ensino Fundamental, salientando a importância desta etapa da educação, haja vista não estar resumida em unir letras e desvendar códigos, mas também ampliar os modos de comunicação e de compreensão de mundo.

\section{O letramento no cotidiano da sala de aula}

Relembrando que o objetivo desse texto é apresentar e discutir a forma como os professores dos três primeiros anos do Ensino Fundamental têm utilizado o espaço de sala de aula como um recurso para oportunizar propostas de letramento, neste item vamos trazer alguns aspectos que a imersão na realidade da escola nos possibilitou compreender. Nessa análise optamos por trazer excertos das entrevistas e dos grupos focais simultaneamente, apresentando a visão das professoras e dos alunos sobre a questão investigada.

Durante a coleta de dados, o que se percebeu foi que práticas tradicionais características de métodos empiristas ficaram bastante evidentes, tanto em falas das professoras, como nas conversas realizadas com as crianças durante os grupos focais.

Sobre a organização da sala de aula, duas das três professoras participantes da pesquisa afirmaram utilizar espelho de classe $^{1}$ em suas turmas, sendo o controle sobre os educandos uma característica dos métodos empiristas, bem como a necessidade do silêncio e da ordem, explícita nas falas:

P3: Bom, porque eu acho que, por terem bastante dificuldade, eles gostam, às vezes, de olhar o trabalho do colega, às vezes têm mais afinidades $\mathrm{e}$ gostam de conversar mais, então eu tento distribuir assim, de modo que isso não aconteça ${ }^{2}$.

\footnotetext{
${ }^{1}$ Um tipo de mapa da sala de aula indicando a localização de cada aluno na classe.

${ }^{2}$ Optamos pela transcrição literal das respostas, sem revisão gramatical, considerando que os dados foram coletados oralmente e nossa intenção é apresentá-los de modo fidedigno.
} 
P2: Bom, eu faço espelho de classe sim, pra poder separar, digamos que tem aluno que fica muito perto do outro, fica a aula inteira conversando [...] E a fila também é por tamanho, eu nunca digo assim "- É fila por chegada", por que eles vêm correndo assim, são agitados [...] assim tento manter eles o mais calmos possível, daí devo dizer que eles melhoraram, porque no primeiro dia de aula foi terrível, mas depois eles tão tomando jeito aos pouquinhos, né, eles vão entrando no ritmo da professora.

Práticas como estas caracterizam o que Becker (2001) define como Pedagogia Diretiva, em que o conhecimento é apenas transmitido pelo professor e o aluno nada tem a contribuir. $\mathrm{O}$ autor explica que:

[...] O que encontramos aí? Um professor que observa seus alunos entrarem na sala, aguardando que sentem e que fiquem quietos e silenciosos. As carteiras estão devidamente enfileiradas e suficientemente afastadas umas das outras para evitar que os alunos conversem. Se o silêncio e a quietude não se fizerem logo, o professor gritará para o aluno, xingará outra aluna até que a palavra seja monopólio seu [...] (BECKER, 2001, p.15-16)

Essas características também ficam explícitas nas falas das crianças que traçam um perfil de aluno que definem como correto: "Não dar bola para os outros", "Fazer as coisas e não incomodar" (C3).

A ausência de trabalhos em grupo observada em ambas as turmas, associadas à exigência de atenção do aluno exclusiva ao professor, também caracteriza as práticas empiristas (BECKER, 1993). Em contrapartida, o Projeto Político Pedagógico da escola orienta como fundamental na ação do professor a promoção de momentos de interações em grupo. Desta forma:

Espera-se que o professor tenha várias competências, sendo que uma delas é saber trabalhar em grupo, oportunizando aos alunos interação e participação, com inovação, criatividade, dinamismo, buscando novas estratégias para alcançar suas metas. Portanto, que ele seja capaz de promover a autonomia, a responsabilidade e o respeito entre os alunos, servindo de ponte para que estes alcancem diferentes saberes, tendo ética e flexibilidade, sem perder sua essência humana, delicadeza e bom humor. (PPP, 2016, p.36).

Ao serem questionadas sobre a utilização de trabalhos em grupo, as três professoras negam já terem feito com a turma: "Ainda não" (P1), "Bem no começo do ano eu não proponho nem faço trabalho com tinta [...]" (P2), "Dificilmente" (P3).

Diante dessas falas percebe-se que mesmo estando no século XXI, em uma era digital, a didática escolar ainda é predominantemente tradicional, onde não são proporcionados materiais diversificados ou atividades inovadoras. Em momentos por questão de falta de recurso, mas outros apenas por questão de metodologia, o que é uma opção pedagógica. 
Amparadas nos estudos de Becker (1993 e 2001) sobre práticas pedagógicas e construção do conhecimento, compreendemos a necessidade da utilização do ambiente escolar para que ocorram as interações, e a partir destas as construções do aprendizado. De acordo com essa concepção, os alunos passam a ser sujeitos ativos dentro de sala de aula, podendo contribuir tanto no modo como acontecerão as aulas, quanto na organização e composição do espaço em que as mesmas se realizarão, pois

[...] as práticas de letramento em sala abarcam também o reconhecimento de que as trocas no coletivo estão contribuindo para o desenvolvimento de cada indivíduo que participa das interações. A mediação que possibilita a construção do conhecimento ocorre alternando-se atividades de leitura e escrita, desenvolvida individualmente ou colaborativamente em duplas ou grupos, na negociação de significados entre colegas e entre o professor e o grupo de alunos. [...] (BARBATO, 2007, p.280).

Embora as evidências mostrassem práticas baseadas em métodos tradicionais, na turma de segundo ano foi notória a utilização de histórias incentivando os alunos à leitura. A seguir, um trecho de um diálogo entre a pesquisadora ${ }^{3}$ e as crianças, durante a realização do grupo focal, que relatavam momentos de exploração de histórias:

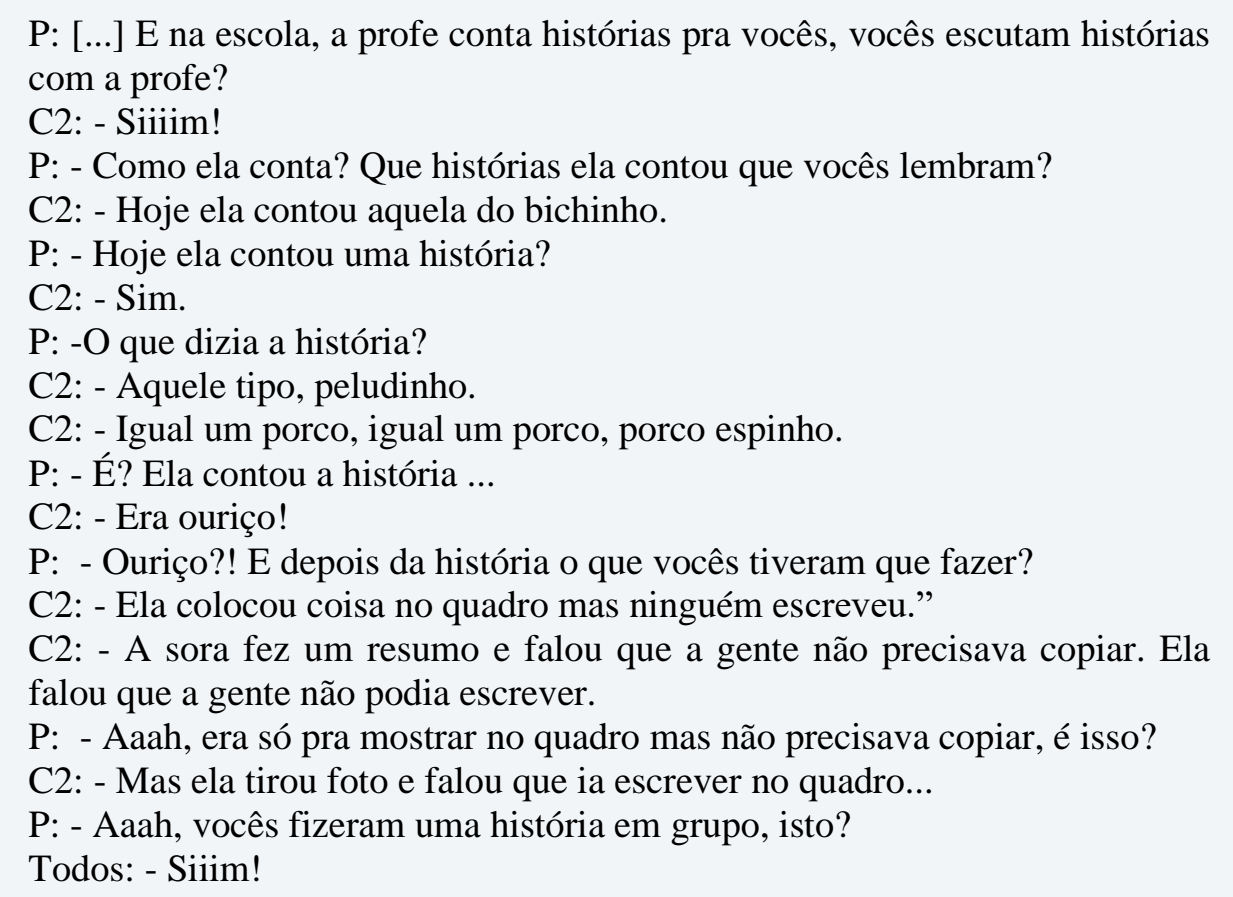

Durante entrevista, a professora responsável pela turma salientou que considera importante o estímulo à leitura para a formação de novos leitores: "[...] leitura de histórias,

\footnotetext{
${ }^{3}$ A coleta de dados empíricos foi realizada por apenas uma das pesquisadoras, por isso o uso do substantivo no singular (pesquisadora) toda vez que referimo-nos às entrevistas, observações e grupos focais, assim como ao diário de campo.
} 
acho isso muito importante porque tu tem que incentivar o aluno a ler, e leitura coletiva, né, e até produção de textos [...]" (P2). Os relatos das crianças e da professora evidenciam que embora os métodos utilizados sejam majoritariamente em torno do processo de alfabetização, com repetições, utilização de sílabas e palavras desconexas, a turma de segundo ano diferenciou-se das demais, que apresentavam propostas de histórias trazidas apenas pela professora de projeto de mediação de leitura da escola. Observemos:

P: [...] E a professora de vocês aqui da sala, ela traz histórias pra vocês, ela conta histórias pra vocês aqui na sala?

C1: - Não.

C1: - Não.

P: - Não?

C1: - Não.

P: - Nunca trouxe? Nunca trouxe nenhum livro assim pra vocês?

C1: - Tem uma que trouxe.

P: - Tem uma que trouxe? Qual?

C1: - Aquela lá daquela sala (Apontando para a Biblioteca da escola)

P: - Da Biblioteca?

C1: - É.

P: - A profe da Biblioteca traz?

C1: - É, a profe $* * * * *$. (Neste momento, fala o nome da professora da Biblioteca).

Embora esses eventos de letramento envolvendo contação e exploração de histórias estivessem sendo realizadas uma vez por semana, apenas pela professora bibliotecária, responsável pelo projeto de mediação de leitura da escola, sabe-se que é de extrema importância a realização diária de leitura nos anos iniciais, utilizando diferentes estratégias. Concordamos com Demo (2007, p.23) quando afirma que:

A escola existe para iniciar as crianças na leitura do mundo, não para as disciplinar em quatro paredes através de métodos impositivos, cuja pecha maior não é servir à criança, mas ao contrário. Afinal, ler é mais importante que decifrar. O sentido do texto é mais relevante que o som do texto. [...]

Nesta perspectiva, Demo também ressalta a importância das práticas letradas objetivando a formação de sujeitos críticos, pensantes e com posicionamento: "[...] Não se lê para aceitar, reverenciar, mas para se contrapor, não no sentido banal de apenas dizer que discorda, mas no sentido profundo de aceitar o desafio de transformar a leitura em alavanca de transformação social. [...]" (DEMO, 2007, p.18).

As práticas de leitura devem ser realizadas por meio de propostas lúdicas que despertem o interesse do educando. O que se percebeu, infelizmente, é a presença de práticas pedagógicas onde apenas se opta pela consolidação da alfabetização, de forma mecânica e 
repetitiva. Exigências de leitura, de forma autoritária e não prazerosa, o que acaba por provocar no sujeito aprendente o desinteresse e o desestímulo por essas práticas. Neste sentido:

[...] como janelas para o mundo, os sistemas educativos têm, muitas vezes e infelizmente, as cortinas fechadas. [...] Quando o sistema educativo exclui ou inclui só parcialmente, pelas suas limitações pedagógicas e logísticas, aqueles que mais poderiam se beneficiar da sua existência e funcionamento, o processo de desenvolvimento social é estancado. [...] (PRETO-BAY,2007, p.19)

Desta forma, percebe-se o papel do educador no ciclo de alfabetização: possibilitar que seus alunos explorem, analisem e compreendam as mais diversas formas e funções de diferentes tipos de textos, fazendo com que estes tornem-se aptos e confiantes quanto à utilização da escrita no dia a dia. Essas propostas são decorrentes do modo como o professor compreende que ocorre a alfabetização, como explicam os estudos de Ferreiro (1991). Embasamo-nos em Soares (2014) para destacar a importância do desenvolvimento do processo de letramento, e não apenas a consolidação da alfabetização:

Letramento é usar a leitura para seguir instruções (a receita de biscoito), para apoio à memória (a lista daquilo que devo comprar), para a comunicação com quem está distante ou ausente (o recado, o bilhete, o telegrama). [...] Letramento é usar a escrita para se orientar no mundo (o atlas), nas ruas (os sinais de trânsito), para receber instruções (para encontrar um tesouro... para montar um aparelho... para tomar um remédio), enfim, é usar a escrita para não ficar perdido. (SOARES, 2014, p.43)

Todavia, o que se percebeu durante as falas das crianças nos grupos focais foi a ausência da utilização de intervenções pedagógicas que utilizassem de materiais com diferentes formas de comunicação escrita estimulando a ampliação do processo de letramento dos educandos, ou seja, as práticas pedagógicas utilizadas nas turmas participantes da pesquisa apenas davam conta do processo de alfabetização. Um exemplo disso foram os relatos dos educandos quanto à utilização de jornais:

P: - E vocês já fizeram algum trabalho com jornal?

C3: - Não.

C3: - Sim!

P: - Que tipos de trabalhos?

C3: - hããã...Fazer bandeirinha.

P: - Fazer bandeirinha... E com as reportagens que têm nos jornais? Já fizeram algo?

C3: - Sim.

Outros: - Não...

C3: - Sim, daquelas palavrinhas que têm que recortar... 


\section{P: - De recortar palavras só? \\ C3: - Sim.}

Ao observar esses relatos dos estudantes do terceiro ano, fica evidente que as estratégias didáticas utilizadas pelas professoras das turmas participantes da pesquisa priorizam atividades de alfabetização por repetição e fragmentação de palavras, não dando espaço para atividades de ampliação do letramento.

Ao utilizarem jornais apenas para recorte de palavras e sílabas isoladas caracterizam em suas intervenções aspectos de métodos de alfabetização por palavração ou silabação que, de acordo com Portes (2012, p.206), consiste na "[...] estimulação dos sentidos por meio da exposição ostensiva de palavras [...]", ou seja, nestes métodos, não há preocupação com a interação com textos, apenas a possibilidade de trabalhar com palavras e fragmentá-las.

O fato de utilizarem jornais para 'fazer bandeirinhas' também evidencia estas características já que o portador do texto jornalístico fica sendo utilizado apenas como um material reciclável, mas não é atentado para a sua função nem explorados seus textos de cunho informativo, embora a Base Nacional Comum Curricular assegure que sejam explorados os mais diversos tipos de texto, inclusive reportagens, impressas ou digitais.

A legislação é bastante clara ao determinar que o fazer pedagógico dos três primeiros anos seja em torno dos dois processos, alfabetização e letramento, de forma lúdica e prazerosa, respeitando as características e necessidades desta fase da infância. Assim, "A escola deve disponibilizar espaços, brinquedos, materiais didáticos e equipamentos que configurem o ambiente alfabetizador compatível com o desenvolvimento da criança nessa faixa etária." (PARECER CEED/RS N 752/2005). Porém, o que se observou nos espaços de sala de aula foram posturas bastante tradicionais, não favoráveis à brincadeira nem às interações. Conforme registros no diário de campo:

Sala com aparelho de ar condicionado, classes e cadeiras dispostas uma atrás da outra (sem duplas); uma caixa de jogos em cima do armário da professora, que é trancado pela mesma. Um mural de tecido na parede com os números de 1 a 30 pintados, outro com o alfabeto em script e cursivo e um relógio analógico. (DC, 01.03.2019)

Em outros registros do diário de campo aparecem mais trechos confirmando esse espaço pouco utilizado pelas professoras, como: "sala ampla, classes enfileiradas individualmente, quadro branco e um quadro negro no fundo. Armário da professora." (DC, 07.03.2019). E ainda, "As crianças estão sentadas em fileiras, uma atrás da outra. Há um alfabeto no saquinho colado no alto da parede. Um relógio 'parado' sem funcionar. Não há 
outros cartazes, nem jogos ou brinquedos." (DC, 19.03.2019). Afirmações como essas reforçam as evidências de que, além das professoras não utilizarem do espaço como um recurso a favor do processo de letramento, suas posturas empiristas impedem que as crianças tenham liberdade de explorar esse espaço:

P: - E vocês podem fazer atividades assim sentados no chão ou sentados na cadeira?

C3: - Sempre na cadeira.

P: - Sempre na cadeira... - E vocês têm alguns momentos para brincar na sala?

Todos, em sintonia: - Nããão...

P: - Não pode brincar na sala?

C3: - Não.

P: - E que tipos de brincadeiras vocês gostariam que fossem feitas?

C3: - Qualquer jogo, jogo de tabuleiro...

C3: - De pintar...

P: - O que mais?

C3: - Desenhar!

C3: - É, desenhar! (Animado).

P: - E vocês têm uma caixa de jogos lá na sala, vocês não brincam?

C3: - Não, não pode. (Expressão de negação).

C3: - Não.

C3: - A sora não deixa!

C3: - E ela não dá.

C3: - E ela não gosta!

C3: - A sora não deixa, por causa que se pedir ela vai xingar...

P: - Se pedir ela xinga?

C3: - Sim

Os alunos deixam claro durante o diálogo que mesmo possuindo jogos na sala estes não são utilizados por eles. Outro aspecto importante que deve se atentar nestas falas é o desejo por atividades simples, como desenho e pintura, valorizados pelos alunos e, nesse caso, não utilizados mais no Ensino Fundamental. Com isso, as crianças passam então a demonstrar saudades da Educação Infantil, época em que essas atividades eram possíveis, como podemos ver no excerto a seguir:

P: - E vocês viram que eles tão fazendo trabalho em grupo né? Vocês já fizeram trabalho em grupo?

C2: - Nessa (turma) não.

C2: - Não!

C2: - Nessa não. Mas só na do pré.

P: - E agora aqui, o que estão fazendo?

C2: - Brincando de uma rodinha!

C2: - Eles estão brincando de ovo choco.

P: - E nessa sala, nessa turma que estão já brincaram de roda?

C2: - Só no pré.

P: - Vocês costumam sentar em roda, ficar no chão?

C2: - Não... [...] 
C2: - Eles tão pintando as mãos.

P: - Eles estão pintando né, estão sujos de tinta. Vocês já fizeram trabalho com tinta?

C2: - Não!

C2: - Não, só no pré.

$\mathrm{Na}$ entrevista, a professora do segundo ano afirmou que não realiza trabalhos com tinta, e as três relataram não propor trabalhos em grupo. Atividades de interação entre os pares não são realizadas, bem como atividades que utilizem do espaço e o auxílio dos educandos na sua composição e organização:

P: [...] E assim ó, sobre a sala de vocês o que vocês gostariam que tivesse na sala de vocês ou que não é tão legal?

C2: - Alfabeto, números...

P: - Não tem ainda o alfabeto nem números? E vocês queriam que ter?

Todos: - Sim!! (Eufóricos)

P: - E vocês queriam ajudar a fazer ou queriam que viesse assim, em desenhos...

C2: - A gente queria fazer!

C2: - A gente queria ajudar a fazer!

C2: - Pintar as letras!

Não podendo realizar estes tipos de atividades diferenciadas, os educandos passam diariamente a realizar atividades de alfabetização, com palavras desconexas, não possuindo apoio de nenhum gênero textual ou tendo alguma relação com o contexto em que estão inseridas. Apenas exercícios, com palavras, letras, sílabas e cópia: "Exercícios no quadro- 1) Completar o alfabeto [...] 2) [...] pintar as iniciais correspondentes a desenhos [...] 3) Ligar figuras a suas palavras-nomes [...]" (DC 06.03.2019); "Atividade no quadro: desenhos com sílabas diversas, onde cada um teria que circular a sílaba inicial correspondente [...]” (DC, 08.03.2019). Atividades estas que aguçam a pesquisadora à reflexão:

Observo essa atividade bem semelhante aos métodos de palavração e silabação onde são exemplificadas nos exercícios, palavras que não fazem relação com nada que estejam estudando, apenas para se identificar a sílaba, que é entendida como a representação da fala. (DC, 08.03.2019)

Em apenas uma das três turmas foi observado um momento de brinquedo livre para as crianças após a realização das tarefas. Mesmo sendo crianças e a legislação assegurando a necessidade do ensino baseado na ludicidade, o que se observou foi um distanciamento entre ambos. Durante a realização da observação a pesquisadora registrou que:

Por mais que tenham tido um espaço de tempo para brincarem, foi possível observar que a ludicidade não se fez presente nas práticas pedagógicas que se dirigiam para o processo de alfabetização e ampliação do letramento, mas 
sim como momentos distintos: primeiro a atividade de alfabetização na sala de aula, e só depois brincar, como se esses dois momentos não pudessem ocorrer simultaneamente. (DC, 26.03.2019)

Embora se saiba que os educandos inseridos nos anos iniciais do Ensino Fundamental são crianças, e que são movidas pela curiosidade embasada pelo lúdico, o que se observou nas três turmas foi a ausência de momentos em que a ludicidade estivesse presente no processo de aprendizagem, tornando-o significativo. Durante um dos encontros foi possível observar que as propostas lúdicas e o letramento estavam sendo bem mais trabalhados em um espaço não escolar. Assim:

P: - E o que quer dizer esse símbolo aqui? (Mostrando uma placa de trânsito)

C3: - Por causa que a gente não pode dobrar e tem que respeitar o sinal.

$\mathrm{P}$ : - Onde vocês viram isso daqui?

C3: - Ali!

C3: - Ali na praça.

C3: - Ali perto da ponte...

P: - E aqui na escola vocês já fizeram algum tipo de trabalho que tivesse isso daqui?

Todos: - Não.

C3: - Só no projeto!

P: - Lá no projeto tem?

C3: - Tem!

P: - E aqui, o que essas crianças tão fazendo aqui?

C3: - Jogando joguinho que eu já joguei quando era lá da outra sala...

C3: - Já joguei lá no projeto!

C3: - Eu também!

P: - E aqui na sala não?

C3: - Não!

P: - E nessa turma então, não tem joguinho...

C3: - Tem jogo, só que ninguém joga por que a sora não deixa...

P: - E o que é isso daqui?

C3: - É um negócio da Mônica, cheio de palavras...

$\mathrm{P}$ : - Onde se encontra isso daqui?

C3: - No livro...

P: - E como é o nome do livro que tem isso daqui?

C3: - Mônica.

C3: - É, da Mônica!

P: - Os gibis. Vocês já puderam usar gibis aqui na escola?

Todos: - Não...

P: - Não? E em casa, vocês têm gibis?

C3: - Não. Só no projeto!

C3: - É, no projeto tem! 
O que se analisa neste caso é que as crianças que participam de projetos sociais ${ }^{4}$ de contraturno escolar vivenciam momentos que possibilitam a ampliação do processo de letramento, o que não tem sido oportunizado pela escola. Assim, a realidade observada evidenciou que embora o direcionamento da legislação seja o de proporcionar, durante o bloco pedagógico, os processos de alfabetização e letramento em concomitância, nas práticas observadas os processos não se desenvolvem conjuntamente, e sim, separadamente, quando a alfabetização acaba sendo o foco principal da escola, e o letramento se desenvolve em experiências fora desta. Novamente cabe lembrar o que explica Soares (2017, p. 44):

Dissociar alfabetização e letramento é um equívoco porque, no quadro das atuais concepções psicológicas, linguísticas e psicolinguísticas de leitura e escrita, a entrada da criança (e também do adulto analfabeto) no mundo da escrita ocorre simultaneamente por esses dois processos: pela aquisição do sistema convencional de escrita - a alfabetização - e pelo desenvolvimento de habilidades de uso desse sistema em atividades de leitura e escrita, nas práticas sociais que envolvem a língua escrita - o letramento. (Grifos no original).

Na sequência estarão acopladas as considerações finais deste trabalho, com o desfecho final, trazendo respostas às dúvidas que nortearam todo o processo de pesquisa.

\section{Considerações finais}

Questionamentos acerca da prática pedagógica dos professores do ciclo de alfabetização, sobretudo o que diz respeito ao processo de letramento dos educandos e a utilização do espaço de sala de aula a favor deste, fomentaram o processo de pesquisa.

Sabendo do quanto a composição e exploração do espaço é importante para as crianças, bem como o que a legislação indica quanto à sua organização nos anos iniciais, a pesquisa buscou observar de que forma esse espaço estava sendo utilizado pelos professores com o objetivo de auxiliar no processo de letramento dos educandos.

O que se observou, todavia, foram divergências entre as orientações das Diretrizes (DCN) e dos estudos sobre letramento, com a realidade de sala de aula dos três primeiros anos, a prática: embora os sujeitos inseridos no início do Ensino Fundamental estejam na fase da infância, e a legislação determine que os processos de ensino e aprendizagem se deem através de intervenções lúdicas, não foi possível, durante as observações, constatar tais

\footnotetext{
4 A maioria das crianças integrantes do grupo focal participava de um projeto social missionário, mantido por uma instituição religiosa, ofertado no contraturno escolar para estudantes do bairro em condição de vulnerabilidade social.
} 
práticas. Os momentos de jogos, brincadeiras, atividades coletivas e divertidas que tornam os conhecimentos em torno da língua escrita, foco dos três primeiros anos, bem mais significativos aos educandos, não fizeram parte das aulas. O que acontecia na realidade observada era a separação entre atividades escolares e brincadeiras, como se não fosse possível que ambas acontecessem ao mesmo tempo e gerassem conhecimento.

Essas características marcam, então, um processo de ruptura entre a Educação Infantil e o Ensino Fundamental, que embora devam ser compreendidos como processos lineares de continuidade, os momentos de brincadeira ficaram apenas nas lembranças das crianças que saudosas relembravam da Educação Infantil em suas falas e traziam o Ensino Fundamental como momento de escrever, repetir e copiar.

Outro aspecto importante perceptível nas evidências vindas da coleta de dados foi a ausência de intervenções pedagógicas que envolvessem diferentes gêneros textuais e formas de comunicação escrita. Práticas marcadas apenas pela utilização de palavras desconexas e sua separação silábica. Não explorar diversos tipos de textos impossibilita que o educando compreenda as diferentes funções de cada gênero textual e possivelmente não utilize em sua rotina diária.

Por outro lado, espaços não escolares, neste caso, um projeto social de contraturno escolar para crianças em situação de vulnerabilidade, proporcionava momentos lúdicos e de ampliação de letramento, trazidos nos relatos das crianças durante os encontros de grupo focal. Essas evidências nos possibilitam afirmar que faz-se necessária a preocupação e a implicação de todos os profissionais envolvidos no bloco pedagógico: da gestão escolar para dar suporte e assistência aos docentes, da coordenação pedagógica e dos educadores com o letramento, atentando-se a proporcionar aos aprendentes momentos em que lhes seja possível compreender a função da escrita a ponto de sentirem-se suficientemente seguros para expressarem-se por via desta.

Por isto tornam-se tão importantes pesquisas como esta, que busquem analisar as práticas pedagógicas realizadas em sala de aula no ciclo de alfabetização. Estudos como esse buscam evidenciar a necessidade de que sejam exploradas diferentes estratégias de trabalho por parte dos educadores, que respeitem as particularidades da infância, as especificidades de cada aluno, e que possam contemplar não apenas o processo de alfabetização dos seus educandos, mas também o de letramento, permitindo que estes tenham acesso aos mais diversos gêneros textuais e suas funções para utilizá-los da forma mais adequada. 
Sobretudo, é de extrema importância o respeito à infância: que esta não perca sua essência e que as estratégias em torno da aprendizagem possam respeitá-la. Não podemos empobrecer visão que fazemos da criança como adverte Ferreiro (1991, p. 40) quando “[...] a reduzimos a um par de olhos, um par de ouvidos, uma mão que pega um instrumento para marcar e um aparelho fonador que emite sons". E o respeito à infância consiste, entre outras questões, em tratar a criança como "um sujeito cognoscente, alguém que pensa, que constrói interpretações, que age sobre o real para refazê-lo seu” (FERREIRO, 1991, p. 41). Que possam ser realizadas adequações e adaptações necessárias no espaço físico e no fazer pedagógico, ambos objetivando aprendizagem significativa e uma formação integral do educando, através das possíveis interações e explorações que o espaço de sala de aula lhes possibilite, bem como a utilização deste a favor dos processos de alfabetização e letramento, indispensavelmente em concomitância.

Por fim, e não menos importante, a discussão apresentada nesse texto sobre a forma como os professores do ciclo de alfabetização têm usado o espaço de sala de aula para o letramento evidenciou que são necessários estudos constantes sobre esses temas, abordando não só a fundamentação teórica quando as práticas pedagógicas, o que pode, e deve, ser realizado por meio de formação continuada dos docentes.

\section{REFERÊNCIAS}

BARBATO, Silviane. Letramento: Conhecimento, imaginação e leitura de mundo nas salas de inclusão de crianças de seis anos no ensino fundamental. In: SCHOLZE, Lia (Org.).

Teorias e práticas de Letramento. Brasília-DF: Inep, 2007.

BECKER, Fernando. A epistemologia do professor: o cotidiano da escola. Rio de Janeiro: Vozes, 1993.

BECKER, Fernando. Educação e Construção do Conhecimento. Porto Alegre: Artmed, 2001.

BRASIL, Ministério da Educação. Conselho Nacional de Educação. Parecer CNE/CEB No 11/2010. Diretrizes Curriculares Nacionais para o Ensino Fundamental de 9 (Nove) anos. Brasília, 2010. Disponível em: < http://portal.mec.gov.br/index.php?option=com_docman\&view=download\&alias=6324pceb011-10\&Itemid=30192 >. Acesso em: 16 ago. 2020.

BRASIL, Conselho Nacional de Educação/MEC. Base Nacional Comum Curricular, 2017. 
CARDOSO, Cancionila Janzkovski. A escrita e o outro/interlocutor no dizer das crianças In: SCHOLZE, Lia (Org.). Teorias e práticas de Letramento. Brasília-DF: Inep, 2007.

CARVALHO, Marlene. Alfabetizar e letrar: um diálogo entre a teoria e a prática. Petrópolis, RJ: Vozes, 2005.

DEMO, Pedro. Leitores para sempre. Porto Alegre: Editora Mediação, 2007.

FERREIRO, Emilia. Reflexões sobre alfabetização. 18 ed. São Paulo: Cortez/autores associados, 1991.

HORN, Maria da Graça Souza. Sabores, cores, sons, aromas: A organização do espaço na Educação Infantil. Porto Alegre: Artmed, 2004.

KLEIMAN, Angela (Org.). Os significados do letramento: uma nova perspectiva sobre a prática social da escrita. Campinas, S.P.: Mercado de Letras, Coleção Letramento, Educação e Sociedade, 1995.

MORTATTI, Maria do Rosário Longo, et al. Letrar é preciso, alfabetizar não basta...mais? In: SCHOLZE, Lia (Org.). Teorias e práticas de Letramento. Brasília-DF, Inep,2007.

PERES, Eliane. A infância para além da Educação Infantil: Construindo uma nova cultura escolar para a alfabetização das crianças de 6 anos. In BARBOSA, Maria Carmen Silveira; DELGADO, Ana Cristina Coll et.al. A infância no Ensino Fundamental de 9 anos. Porto Alegre: Penso, 2012.p.59-68

PORTES, Luiza A. F. Por um construtivismo à brasileira: Questões complementares sobre o sujeito da psicogênese. In: SENNA, Luiz A. G. (Org.). Letramento: princípios e processos. Curitiba: Intersaberes, 2012.p.197-218

PRETO-BAY, Ana Maria Raposo. Acesso social, práticas educativas e mudanças teóricopedagógicas ligadas ao gênero textual. In: SCHOLZE, Lia (Org.). Teorias e práticas de Letramento. Brasília-DF, Inep, 2007.

RANGEL, Jurema Nogueira Mendes. Leitura na escola espaço para gostar de ler. Porto Alegre, Editora Mediação, 2012.

RIO GRANDE DO SUL. Conselho Estadual de Educação. Parecer No 752/2005. Manifestase sobre o ingresso obrigatório a partir dos 6 anos de idade no ensino fundamental de nove anos de duração. Determina procedimentos a serem adotados. Disponível em: <http://www.ceed.rs.gov.br/busca=parecer\%2520752\%252F2005;1> Acesso em: abr. 2019

SOARES, Magda. Letramento: um tema em três gêneros. Belo Horizonte, Autêntica Editora, 2014.

SOARES, Magda. Alfabetização e letramento. 7. ed. São Paulo: Contexto. 2017. 


\section{SOBRE AS AUTORAS:}

\section{Lucia Hugo Uczak}

Doutora em Educação pela Universidade Federal do Rio Grande do Sul (UFRGS). Professora Adjunta da Universidade Feevale, docente do Curso de Pedagogia, vinculada à pesquisa "Os 'nós' da leitura e da escrita sob investigação - ações e intenções." E-mail: lucia.hugo@yahoo.com.br

(iD) http://orcid.org/0000-0003-1336-0083

\section{Karine Oliveira Faller}

Pós-graduanda em Administração, Supervisão e Orientação Escolar, e Alfabetização e Letramento, ambos os cursos pela Sociedade Educacional Leonardo Da Vinci (Uniasselvi), Indaial-SC. Colaborou com a pesquisa "Os 'nós' da leitura e da escrita sob investigação ações e intenções.” E-mail: senhoritakarine@ @hotmail.com

(iD) http://orcid.org/0000-0003-3514-9297 